\title{
Modification of ITO surface using aromatic small molecules with carboxylic acid groups for OLED applications
}

\author{
Ali Kemal Havare a,b, Mustafa Can ${ }^{b}$, Serafettin Demic ${ }^{b, *}$, Salih Okur $^{\mathrm{a}, *}$, Mahmut Kus ${ }^{\mathrm{c}}$, \\ Hasan Aydın ${ }^{a}$, Nesli Yagmurcukardes ${ }^{a}$, Suleyman Tari ${ }^{d}$ \\ a Physics Department, Izmir Institute of Technology, Urla/Izmir, Turkey \\ ${ }^{\mathrm{b}}$ Energy Department, Institute of Solar Energy, Ege University, Bornova/Izmir, Turkey \\ c Selçuk University, Advanced Technology Research and Application Center, Turkey \\ ${ }^{\mathrm{d}}$ Microphysics Laboratory, Department of Physics, University of Illinois at Chicago, USA
}

\section{A R T I C L E I N F O}

\section{Article history:}

Received 17 February 2011

Received in revised form 3 August 2011

Accepted 8 September 2011

Available online 15 October 2011

\section{Keywords:}

Self-assembled

OLED

Hole injection

\begin{abstract}
A B S T R A C T
4-[(3-Methylphenyl)(phenyl)amino]benzoic acid (MPPBA) was synthesized in order to facilitate the hole-injection in Organic Light Emitting Diodes (OLED). MPPBA was applied to form self-assembled monolayer (SAM) on indium tin oxide (ITO) anode to align energy-level at the interface between organic semiconductor material (TPD) and inorganic anode (ITO) in OLED devices. The modified surface was characterized by X-ray photoelectron spectroscopy (XPS), atomic force microscopy (AFM) and Kelvin probe force microscopy (KPFM). KPFM was used to measure the surface potential and work function between the tip and the ITO surface modified by SAM technique using MPPBA. The OLED devices (ITO/MPPBA/TPD/Alq $/ \mathrm{Al}$ ) fabricated with SAM-modified ITO substrates showed lower turn-on voltages and enhanced diode current compare to the OLED devices fabricated with bare ITO substrates.
\end{abstract}

Crown Copyright $\odot 2011$ Published by Elsevier B.V. All rights reserved.

\section{Introduction}

Interest on organic light-emitting device (OLED) has been grown progressively during the last decade due to their potential applications as commercial devices in organic electronics [1-5]. The interfacial phenomenon such as poor adhesion [6] is an important parameter in the performance and stability of an OLED device. Therefore, a variety of interfacial treatments have been applied in both cathode/organic [7,8] and anode/organic [9] interfaces to modify the ITO surface in order to enhance the efficiency of OLED devices [10]. Self-assembled monolayer technique (SAM) provides various kinds of functionalities for the hydroxyl groups present on ITO surface by using different organic compounds having various functional groups such as phosphonic acids [11] and carboxylic acids [12]. Moreover the other functions of SAMs reported in the literature for OLED applications include the formation of current blocking layer [13] or a moisture penetration blocking layer [14,15], a dipolar surface layer to enhance charge injection [16], changing the work function of ITO [17] and enhancing the adhesion and stability of HTL layer [18]. ITO surface has been modified with SAM technique using suitable materials for hole

\footnotetext{
* Corresponding authors. Tel.: +90 232750 7706x7675; fax: +90 2327507707. E-mail addresses: serafettin.demic@ege.edu.tr (S. Demic), salihokur@iyte.edu.tr (S. Okur).
}

injection to improve the interfacial compatibility [19] with charge transfer at the interface between ITO and organic hole-transport layer (HTL) [20]. To enhance such charge transfers in an OLED device, thereby improving turn-on voltage, brightness, and external quantum efficiency, coating of triarylamine-based molecules with trichlorosilane-binding groups on ITO as nanoscale layers were performed in the literature [21-23]. But, it is a very well-known fact that such kind of silane derivatives and trialkoxy silanes as well have a tendency to self-condensation in solution [24,25] causing the formation of uniform monolayers difficult.

In this work, a SAM molecule, 4-[(3methylphenyl)(phenyl)amino]benzoic acid (MPPBA), was synthesized as hole injection layer (Scheme 1) due to its anchoring carboxylic acid functional group and triarylamine structure to enhance charge injection. MPPBA, as a monolayer at the interface between ITO surface and TPD (i.e. the hole transfer layer material), is expected to increase the number of inelastic tunneling channels over its $\pi$-conjugated structure improving the hole injection by modifying work function of ITO and HOMO level of HTL material. The carboxylic acid functional group on MPPBA molecule was used to be anchored by hydroxyl groups present on ITO surfaces for the formation of ester bonds, and thus, modification of ITO surface is achieved chemically by self-assembly process.

The surface morphologies of ITO surface before and after SAM modification were characterized by atomic force microscopy (AFM) and X-ray photoelectron spectroscopy (XPS). Kelvin probe force 


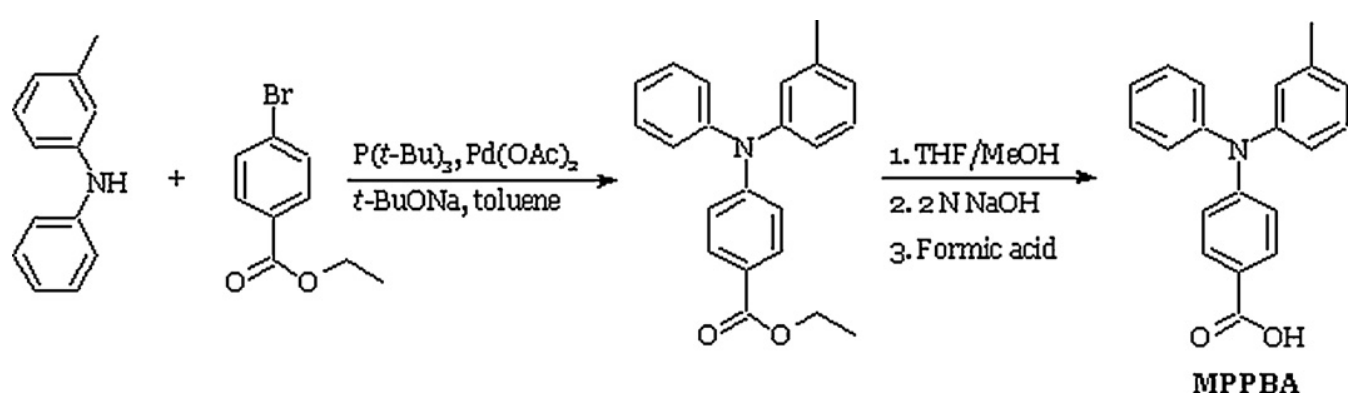

Scheme 1. Synthesis and molecular structure of MPPBA molecule.

microscopy (KPFM) was used to monitor the change in the surface potential and work function of ITO surface before and after modification process. The experimental results showed a decrease in the turn-on voltage and enhancement in the diode current of OLED devices fabricated from SAM-modified ITO substrates when compared to those devices made with bare ITO substrates.

\section{Materials and methods}

\subsection{Materials}

ITO coated glasses with a surface resistivity of $15-25 \Omega /$ sq, tris(8-hydroxyquinoline) aluminum $\left(\mathrm{Alq}_{3}\right)$ (with 99.995\% trace metals) and $N, N^{\prime}$-bis(3-methylphenyl)- $N, N^{\prime}$-diphenylbenzidine (TPD, 99\%) were purchased from Sigma-Aldrich. In the fabrication of OLED devices, Al metal with a purity of $99.99 \%$ was used as cathode contact material. Electrochemistry of MPPBA coated on ITO surface was studied using cyclic voltammetry (CV). CV voltammograms were recorded using $\mathrm{CH} 660 \mathrm{~B}$ model potentiostat from $\mathrm{CH}$. Platinum wire $(\mathrm{Pt})$, glassy carbon (GCE) and $\mathrm{Ag} / \mathrm{AgCl}$ electrodes were used as counter electrode (CE), working electrode (WE) and reference electrode $(\mathrm{RE})$, respectively. $0.1 \mathrm{M} \mathrm{TBAPF}_{6}$ in acetonitrile solution was used as supporting electrolyte. Sweep rate was kept constant at $0.2 \mathrm{~V} / \mathrm{s}$. Ferrocene/ferrocenium couple was used as internal reference.

For the determination of various parameters such as luminance efficiency, luminous power efficiency and external quantum efficiency of OLED devices, integrating sphere was used. A masking was installed at the backside of the OLED devices (cathode or inverse of forward viewing direction) with black paint to eliminate edgeemitted lights. A calibrated detector was used with a spectrometer software (QE65000 Ocean Optics) while measuring the luminance of OLED devices.

\subsection{Synthesis of MPPBA [30,31]}

To a mixture of $N$-(3-methylphenyl)- $N$-phenylamine (1.1 g, $6.4 \mathrm{mmol}$ ) and ethyl 4-bromobenzoate $(1.3 \mathrm{~g}, 6 \mathrm{mmol})$ in dry toluene $(18 \mathrm{ml})$ was added $t$-BuONa $(0.75 \mathrm{~g}, 7 \mathrm{mmol}), \mathrm{P}(t-\mathrm{Bu})_{3}$ $(0.12 \mathrm{~g}, 0.5 \mathrm{mmol})$ and palladium acetate $(0.056 \mathrm{~g}, 0.25 \mathrm{mmol})$ in the given sequence. The resulting mixture was heated to $120^{\circ} \mathrm{C}$ for $28 \mathrm{~h}$. After cooling to room temperature, the reaction mixture was quenched by distilled water $(40 \mathrm{ml})$ and extracted by ethyl acetate $(40 \mathrm{ml})$. The organic phase was washed successively with water, brine, and then dried over anhydrous magnesium sulphate. The crude product was purified by column chromatography (silica gel, dichloromethane:n-hexane, 1:1) to give a light brown oil of ethyl 4-[(3-methylphenyl)(phenyl)amino]benzoate (1.21 g, $60 \%$ ). An aqueous solution of sodium hydroxide ( 5 equiv., $2 \mathrm{~N}$ ) was added to ester (1 equiv.) dissolved completely in methanol and tetrahydrofuran $(1: 1)$ at $0{ }^{\circ} \mathrm{C}$. After stirring for $12 \mathrm{~h}$ at room temperature, the reaction mixture was subjected to vacuum and the residue was dissolved in water. After washing the aqueous phase of crude product with ethyl acetate, the aqueous phase was acidified with formic acid and subsequently extracted with ethyl acetate $(3 \times 25 \mathrm{ml})$. The combined organic layers were dried with sodium sulphate. Removal of the solvent provided the crude product of MPPBA, which was then used without further purification.

${ }^{1} \mathrm{H}$ NMR (400 MHz, CDCl 3 , TMS): $7.91(\mathrm{~d}, 2 \mathrm{H}), 7,31(\mathrm{t}, 2 \mathrm{H}), 7.21$ $(\mathrm{t}, 2 \mathrm{H}), 7.16-7.11(\mathrm{~m}, 2 \mathrm{H}), 6.98(\mathrm{~m}, 6 \mathrm{H}), 2.29(\mathrm{~s}, 3 \mathrm{H})$.

\subsection{Modification of ITO surface by SAM technique}

Before the formation of SAM monolayers of MPPBA molecules on ITO surface, ITO coated glasses were first sonicated successively for $15 \mathrm{~min}$ in detergent solution, and then successively washed with deionized water, acetone and 2-propanol. After drying in $\mathrm{N}_{2}$ stream, the substrates were then treated in oxygen plasma for $30 \mathrm{~min}$ to activate the ITO surface. Just after oxygen plasma treatment ITO coated glass substrates were immediately dipped into a $1 \mathrm{mM}$ ethanolic solution of MPPBA at $20^{\circ} \mathrm{C}$ and kept there for $48 \mathrm{~h}$ in order to ensure the formation of a densely packed monolayer on ITO surface. The substrates were then rinsed with ethanol to remove the residual MPPBA molecules from the ITO surface and finally dried in a stream of $\mathrm{N}_{2}$ gas. The reaction between carboxylic acid head group of MPPBA and ITO is similar to the one occurred between phosphonic acid derivative and $\mathrm{SiO}_{2}[26,27]$ and $\mathrm{TiO}_{2}$ [28]. These oxide surfaces have all similar property, because they all have hydroxyl groups $[17,29]$.

\subsection{Fabrication of OLED devices}

Two different sets of OLED devices were fabricated with a thermal evaporator from NANOVAK Co. (Ankara, Turkey) on top of freshly SAM-modified ITO and oxygen plasma treated bare-ITO substrates with a configuration of ITO/MPPBA/TPD $(50 \mathrm{~nm}) / \mathrm{Alq}_{3}(60 \mathrm{~nm}) / \mathrm{Al}(120 \mathrm{~nm})$ and $\mathrm{ITO} / \mathrm{TPD}(50 \mathrm{~nm}) / \mathrm{Alq}_{3}$ $(60 \mathrm{~nm}) / \mathrm{Al}(120 \mathrm{~nm})$. The organic semiconductors, TPD as HTL material and $\mathrm{Alq}_{3}$ as emitting and electron transport layer (ETL) material were thermally deposited at $4 \times 10^{-5}$ Torr with $0.5 \AA / s$ evaporation rate. Highly pure Al was thermally evaporated to form the top contact at a pressure of $4 \times 10^{-6}$ Torr with a deposition rate of $3 \AA /$ s. Fig. 1 shows the schematic representation of OLED devices fabricated from bare-ITO and SAM-modified ITO substrates.

The surface morphology of bare-ITO and SAM-modified ITO substrates was characterized using a Solver Pro AFM from NTMDT (Russia). The modified surface was also characterized using XPS. During KPFM measurements TiN conducting cantilevers were used to obtain the change in the surface potential and work function of the ITO surfaces before and after modification. $I-V$ characteristics and electroluminescence (EL) data of OLED devices were determined by using 2400 Keithley source meter and QE65000 Spectrometer from Ocean Optics, respectively. 


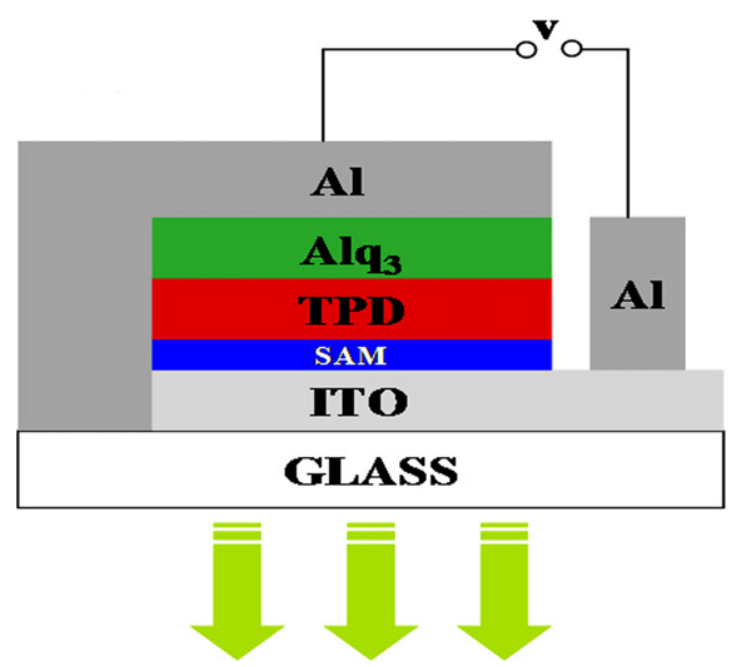

Fig. 1. OLED device structure constructed on SAM-modified ITO coated on a glass substrate.

\section{Results and discussion}

MPPBA was synthesized in three steps according to the previously published procedures [30,31] as described in Scheme 1. It was used as SAM material to form a hole injecting monolayer on the anode material (ITO).

The number of MPPBA molecules self-assembled onto ITO surface is not limited by the surface hydroxyl content [32], since MPPBA can protonate both bridging oxides and hydroxyl-groups already present on the surface. This is a significant advantage to create a strong covalent bond, since the surface hydroxyl content of ITO is notoriously low (approximately $1 \mathrm{OH} \mathrm{nm}^{2}$ ) [33,34]. The bonding carboxylic acid group of MPPBA molecule on ITO is illustrated in Fig. 2.

\subsection{Surface characterization and surface potential measurements using AFM and KPFM}

Local contact potential difference (CPD) between SAM formed on ITO substrates and AFM conductive tip (TiN) was investigated with KPFM.

The surface root mean square (RMS) roughness measured with AFM gives valuable information about the surface morphology of bare- and SAM-modified ITO. AFM topography images of both substrates (bare-ITO and SAM-modified ITO surfaces) are presented
Table 1

Maximum luminance in terms of $L\left(\mathrm{~cd} / \mathrm{m}^{2}\right)$, luminous power efficiency, $n_{p}(\mathrm{~lm} / \mathrm{W})$ and turn-on voltage (V) and the local contact potential difference (CPD) between SAM-modified ITO surface and conductive AFM tip $(\Delta \Phi)$ are given.

\begin{tabular}{llllll}
\hline & Max. $L\left(\mathrm{~cd} / \mathrm{m}^{2}\right)$ & $n_{p}(\mathrm{~lm} / \mathrm{W})$ & Turn-on $(\mathrm{V})$ & $\Delta \Phi(\mathrm{V})$ & RMS $(\mathrm{nm})$ \\
\hline Bare-ITO & 14.8 & 0.016 & 5.5 & 0.066 & 1.50 \\
MPPBA-ITO & 52.9 & 0.12 & 4.5 & 0.286 & 1.45 \\
\hline
\end{tabular}

in Fig. 3(a) and (b). These images of ITO substrates after a careful cleaning procedures show almost similar surface topologies with very close RMS roughness values (bare-ITO: $1.50 \mathrm{~nm}$; SAMmodified ITO: $1.45 \mathrm{~nm}$ as shown in Table 1) indicating no more than a single monolayer is present on both ITO surfaces. Fig. 3c and $d$ shows the surface potential distribution of bare-ITO and of SAM-modified ITO, respectively. The local contact potential difference between TiN tip and bare-ITO was measured as $0.066 \mathrm{~V}$ and it was obtained as $0.286 \mathrm{~V}$ for SAM-modified ITO surfaces using KPFM technique (Fig. 4).

The values obtained from KPFM measurements clarified that the work function of SAM-modified ITO surface increased as a result of forming a single monolayer of MPPBA molecules anchored onto the ITO surface and HOMO level of SAM-modified ITO surface is pushed toward HOMO level of TPD layer. Table 1 shows the CPD data between SAM-modified ITO surface and conductive AFM tip.

\subsection{Cyclic voltammetry results of MPPBA}

Further characterization of SAM-modified ITO surface was carried out by cyclic voltammetry (CV). First, cyclic voltammogram of SAM material (MPPBA) in solution was obtained (Fig. 5, solution phase). MPPBA possesses a single reversible oxidation peak at $1.1 \mathrm{~V}$, which arises from its triarylamine moiety as expected. This behavior can be attributed to the direct attachment of the carboxylic acid group into triarylamine moiety. Its attachment allows the electron density of triarylamine core to be redistributed to the electronwithdrawing carboxylic acid group, so that only a single reversible oxidation peak is observed in the given potential range [35].

Oxidative CV measurement of SAM-modified ITO surface was also performed and its voltammogram is presented in Fig. 5 (solid phase). MPPBA based SAM on ITO surface shows a semi-reversible oxidation peak of triarylamine core as observed in the solution phase. In this case, the oxidation peak was observed at $0.99 \mathrm{~V}$. This slight shift can be attributed to the carbonyl group anchored to ITO surface which decreases the electron affinity of carbonyl group which might cause the formation of unstable oxidized species on<smiles>O=C(O)c1ccc(N(c2ccccc2)c2cccc(O)c2)cc1</smiles><smiles>Cc1cccc(N(c2ccccc2)c2ccc(C(=O)[O-])cc2)c1</smiles>
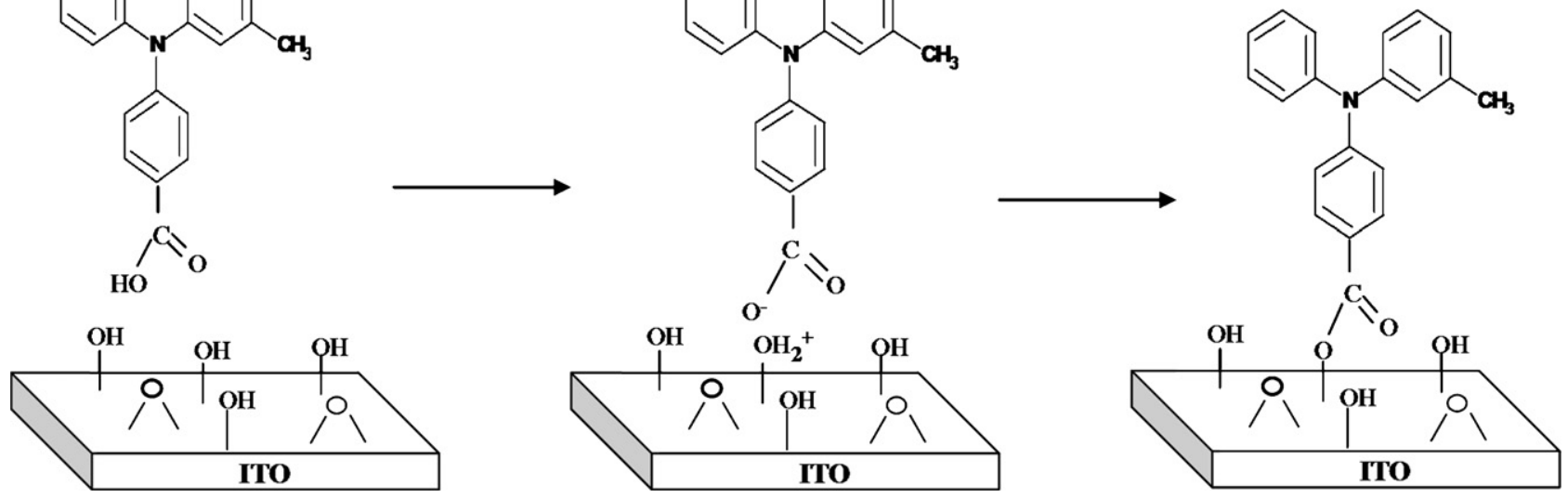

Fig. 2. The illustration of the bonding mechanism between carboxylic acid group of MPPBA molecules and ITO. 

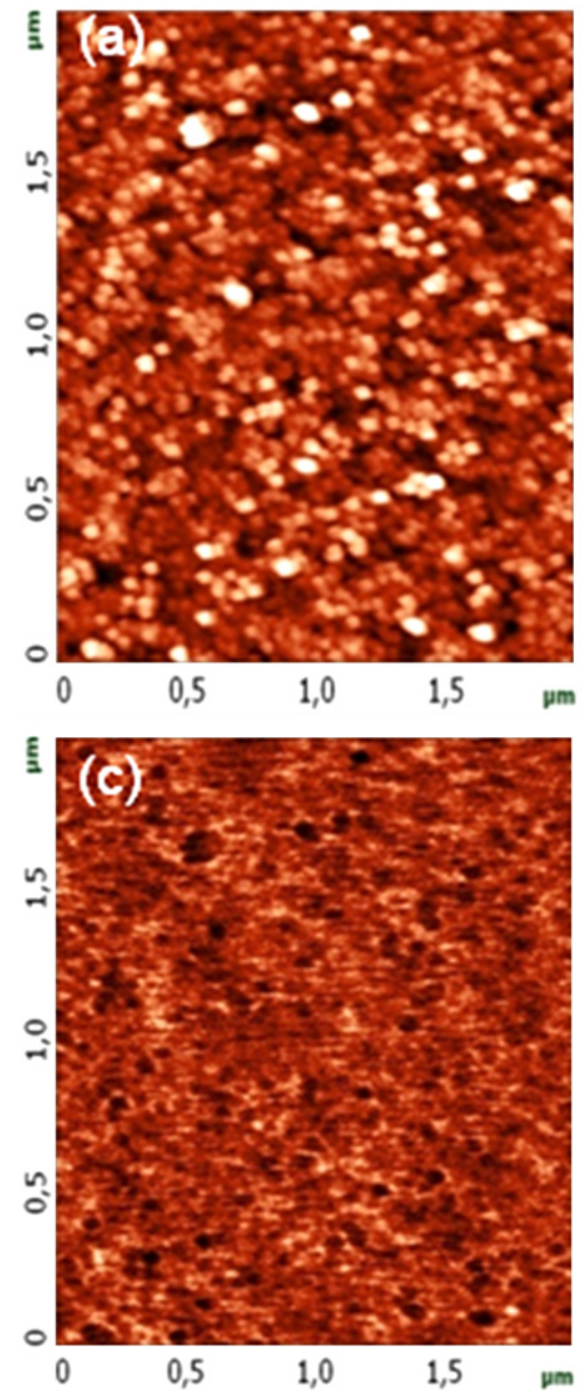
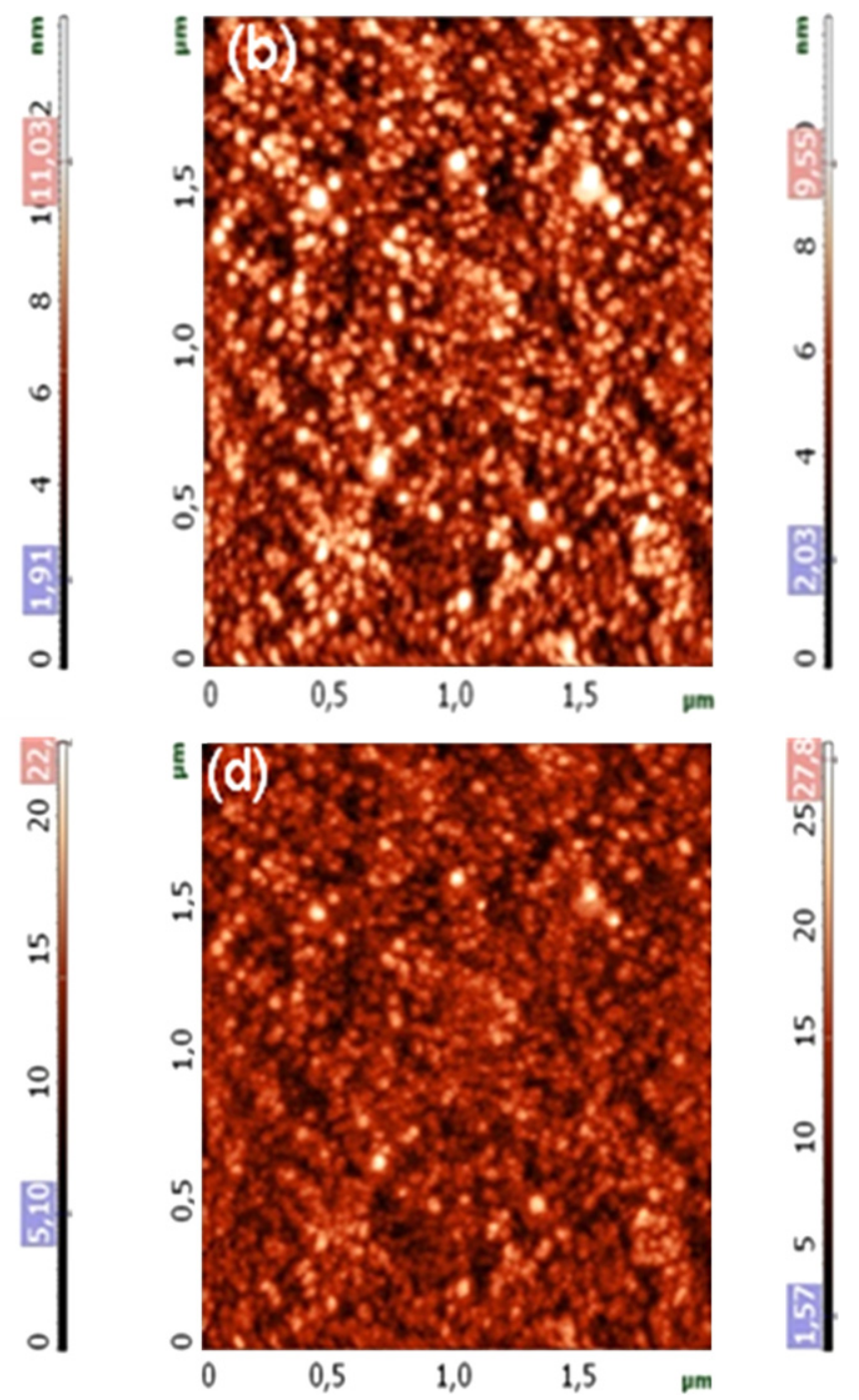

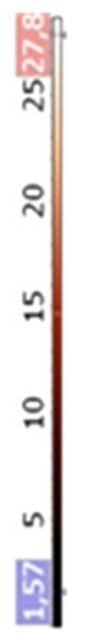

Fig. 3. AFM topography images of bare ITO (a), SAM-modified ITO (b), surface potential distribution of bare ITO (c) and SAM-modified ITO (d).

ITO surface. Then, the change in electron affinity leads to a reduction of oxidation potential as compared to that of solution phase.

HOMO level of MPPBA was calculated from the onset of oxidation potential by the intersection of two tangents drawn at the rising oxidation current and background current in its cyclic

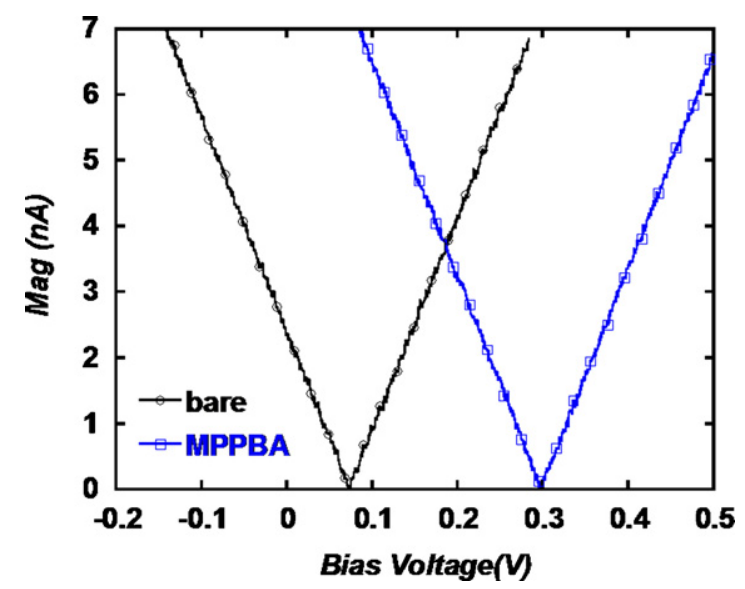

Fig. 4. The local contact potential difference measurement on bare ITO (circles) and SAM-modified ITO substrates (squares) with conductive AFM tip. voltammogram. The HOMO level of MPPBA was found to be $-5.5 \mathrm{eV}$ and $-5.4 \mathrm{eV}$ in solution phase and on ITO surface, respectively. The increase in the value of HOMO level of MPPBA coated ITO may be attributed to the decrease in the surface potential of ITO after SAM formation which will be discussed in the next part.

\subsection{Effect of molecular dipole on ITO work function}

The presence of a molecular dipole plays an important role in the charge-injection properties of SAM layer in OLEDs. This concept has been extensively studied and reported in the previous publications [36-40]. Charge transfer from the COOH head group of MPPBA molecule to ITO surface leads to the formation of $\mathrm{C}-\mathrm{O}$ bond due to electrostatic interaction between positively charged ITO surface and the delocalized electrons in the oxygen atom of carboxylate group in MPPBA molecule [41]. There is a molecular dipole layer present at the interface between ITO and TPD. MPPBA molecules have a chemical bonding on ITO surface, as shown in Fig. 6a. The dipole moment pointing toward the ITO surface effectively shifts ITO work function ( $\left.\phi_{\text {ITO }}\right)$ and decrease the barrier height for hole transfer as shown in Fig. 6b and c. The difference between work functions of anode and the adjacent organic layer determines the energy barrier at the interface during charge transfer from anode to hole transport layer. 

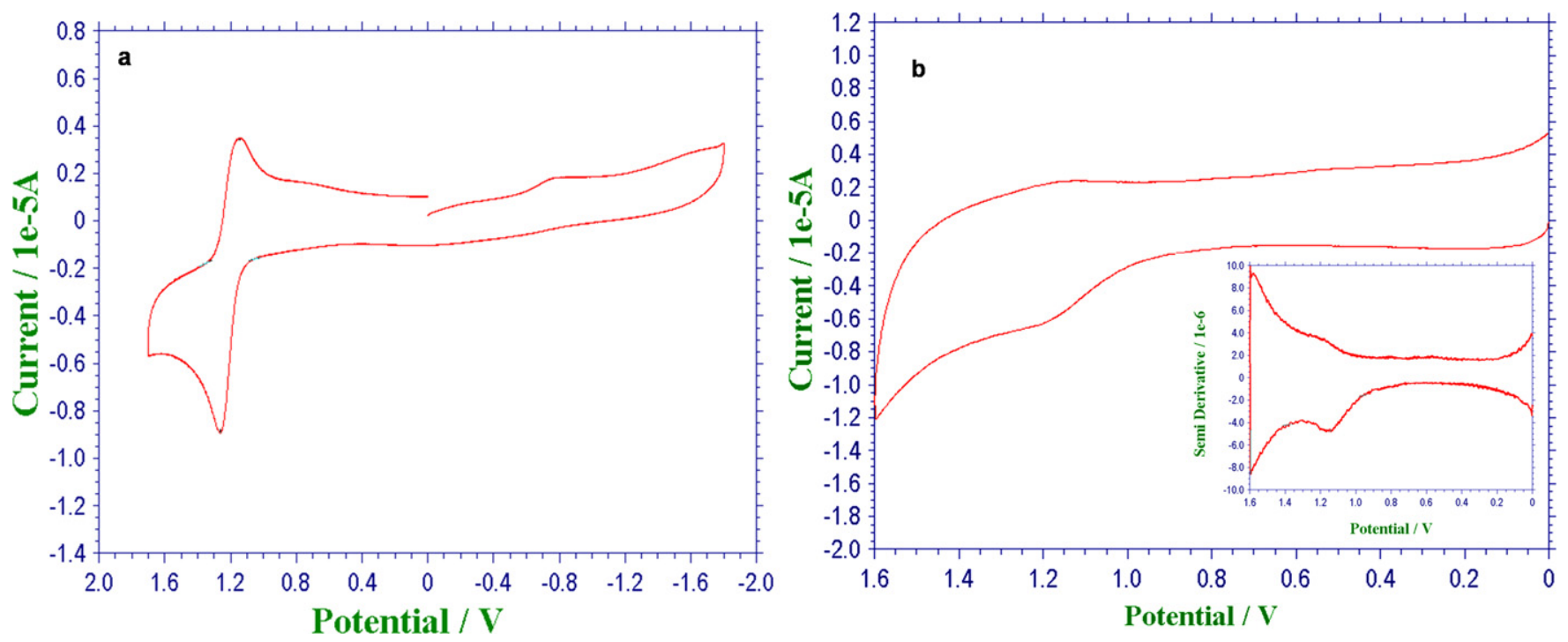

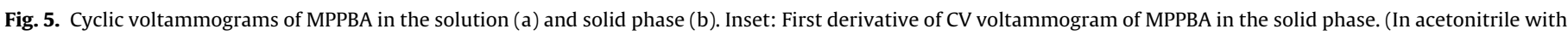
$0.1 \mathrm{M} \mathrm{TBAPF}_{6}$ as the supporting electrolyte with respect to the reference electrode $\mathrm{Ag} / \mathrm{AgCl}$; the scan rate was $0.2 \mathrm{~V} / \mathrm{s}$.)

a)

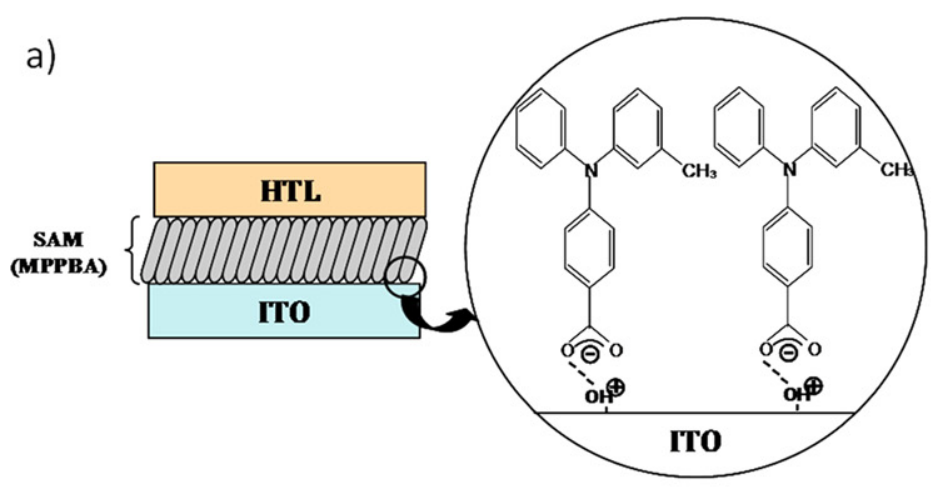

c)

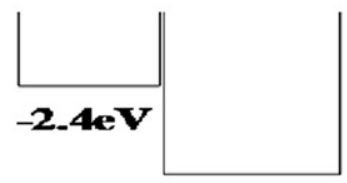

3.1eV

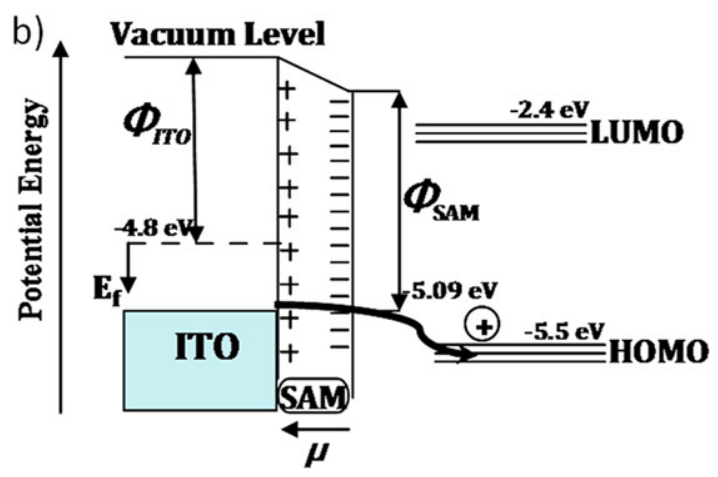

E vac

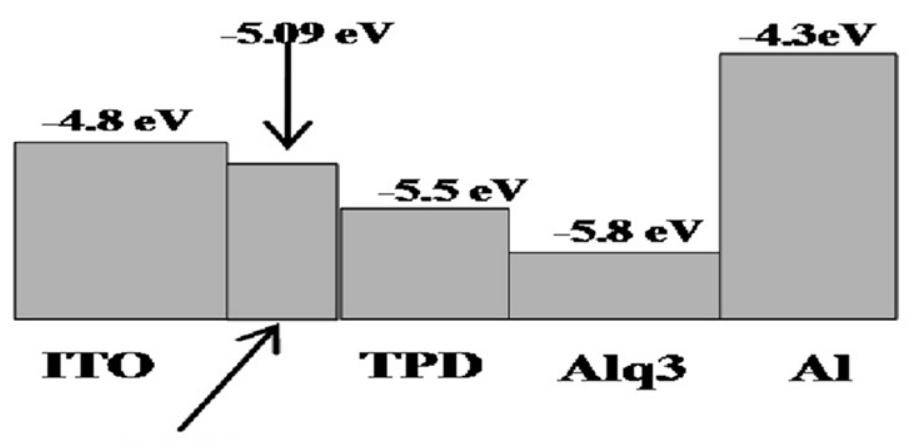

SAM

Fig. 6. The molecular dipolar layer at the interface between ITO and TPD. MPPBA molecules make a chemical bond on ITO surface (a), diagram of the original work function changes due to the layer of dipole molecules present at the ITO surface (b), and energy band diagram of the OLED device (c). 

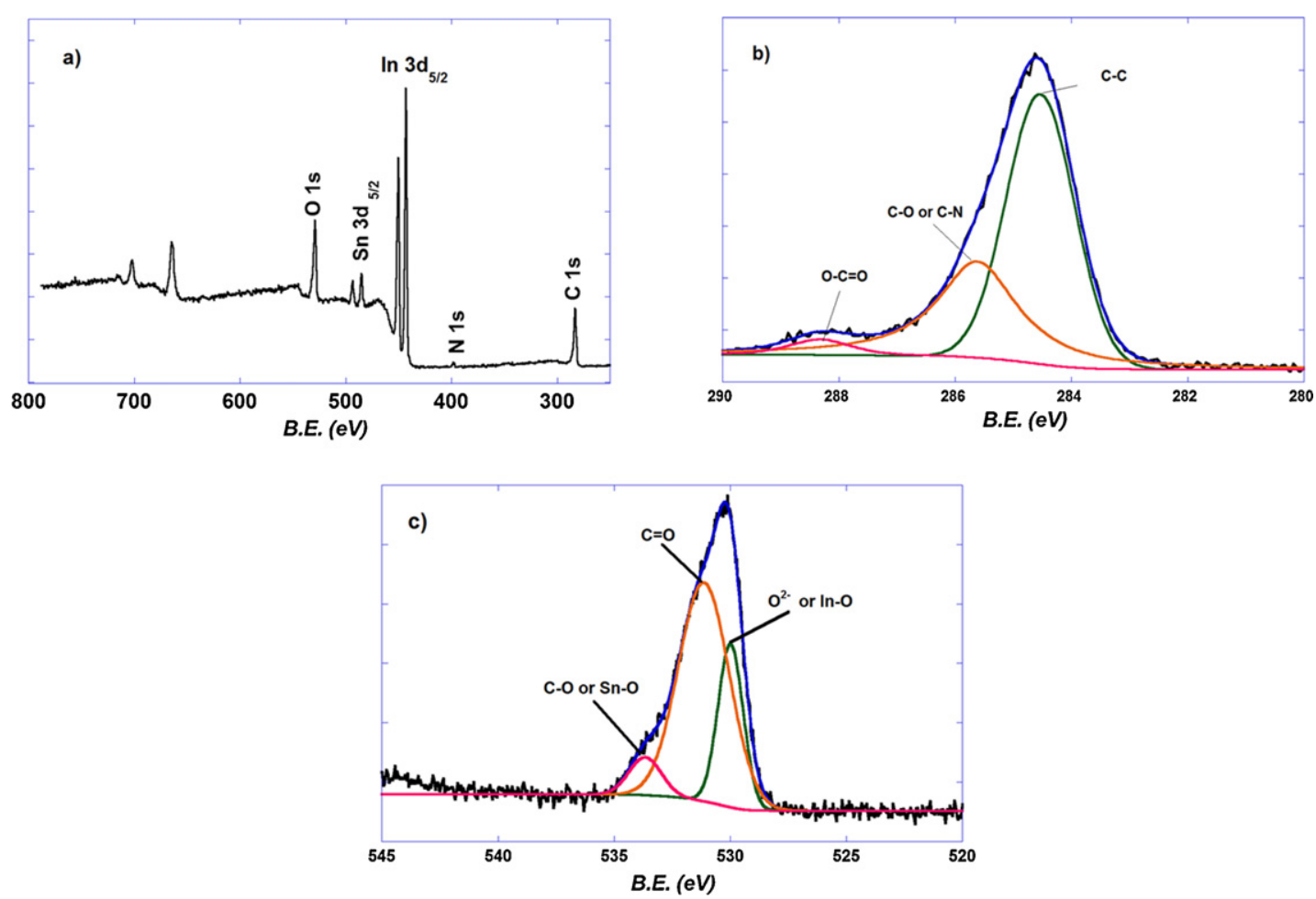

Fig. 7. XPS survey spectrum of SAM-modified ITO surface (a), XPS C 1s spectrum of MPPBA (b), XPS O 1s spectrum of MPPBA (c).

Change in HOMO level of ITO surface after SAM modification using MPPBA can also be determined by using Kelvin Probe measurement. The HOMO energy level of MPPBA by this method was calculated as $-5.09 \mathrm{eV}$. This value is between HOMO level of bareITO $(-4.8 \mathrm{eV})$ and the HTL material of TPD $(-5.5 \mathrm{eV})$. This helps to increase the rate of hole transfer from anode surface to the organic material (TPD) via the SAM layer due to the interface energy states between ITO and TPD.

\subsection{XPS study of MPPBA coated ITO surface}

X-ray photoelectron spectroscopy (XPS) was used to investigate chemical structure of $\mathrm{COOH}$-terminated MPPBA molecules on ITO. Fig. 7(a) shows an XPS survey spectrum of SAM-modified ITO surface after the modification process. The peaks, In $3 d_{5 / 2}$, Sn $3 d_{5 / 2}$, $\mathrm{O} 1 \mathrm{~s}, \mathrm{~N} 1 \mathrm{~s}$ and $\mathrm{C} 1 \mathrm{~s}$ are seen in the spectra with binding energies of 443.6, 485.6, 530.7, 398.4, and $284.6 \mathrm{eV}$, respectively. In and $\mathrm{Sn}$ peaks confirm the existence of a very thin layer of MPPBA molecules. Fig. 7(b) shows a high resolution spectrum of $C 1$ s peak. The $C$ peak was fit with a Shirley background and mixed singlet peak. The peaks at $288.3,285.6$ and $284.6 \mathrm{eV}$ are assigned to $\mathrm{O}-\mathrm{C}=\mathrm{O}$, $\mathrm{C}-\mathrm{N}$ or $\mathrm{C}-\mathrm{O}$ and $\mathrm{C}-\mathrm{C}$ bonds, respectively. The peak at $288.3 \mathrm{eV}$ is a strong indication of the covalent bonding of $\mathrm{O}-\mathrm{C}=\mathrm{O}$ connection formed between $\mathrm{COOH}$ group of MPPBA molecule and hydroxyl group of the ITO surface. This peak is attributed to carbon of carboxyl groups in the formatted molecule. In order to explain the origin of the peaks seen at $285.6,288.3$ and $284.6 \mathrm{eV}$ in C $1 \mathrm{~s} \mathrm{spec-}$ tra, one should refer to the $\mathrm{C} 1 \mathrm{~s}$ spectra in organic compounds.
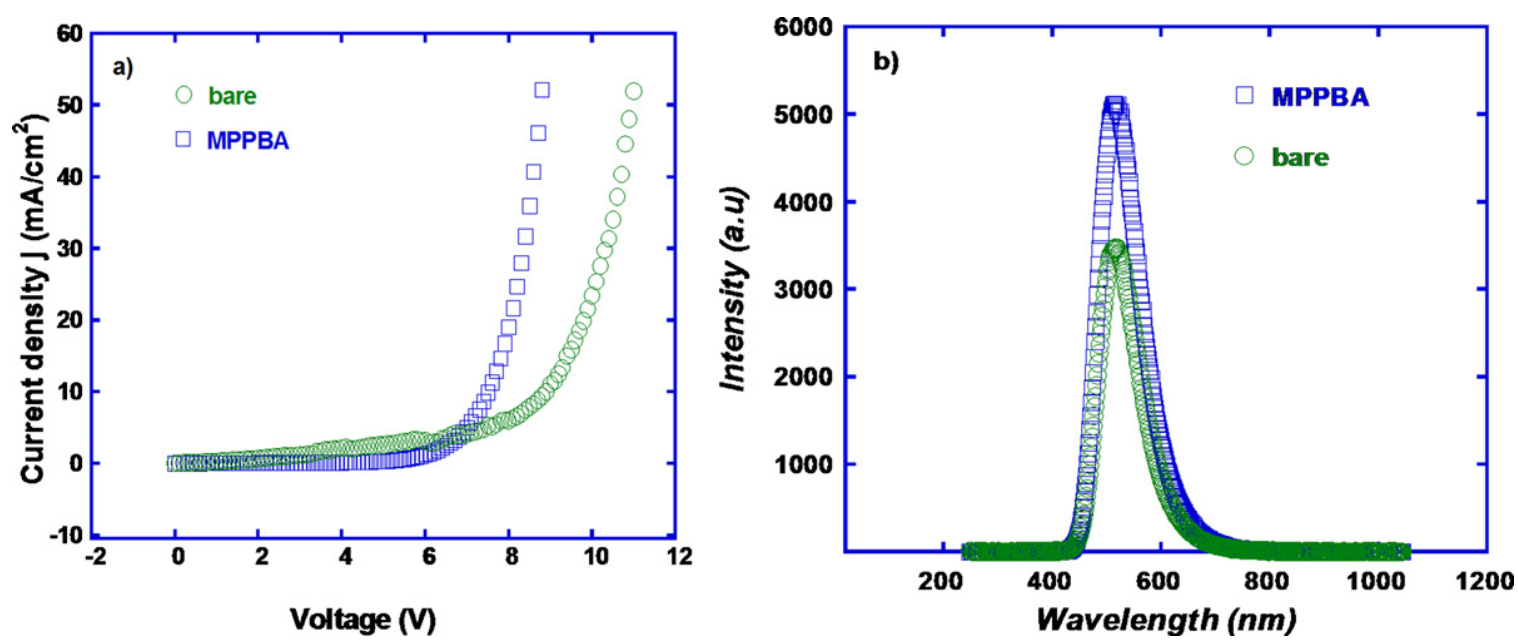

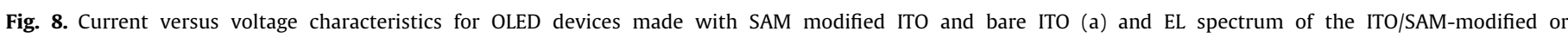
unmodified/TPD/Alq $/$ /Al devices (b). 

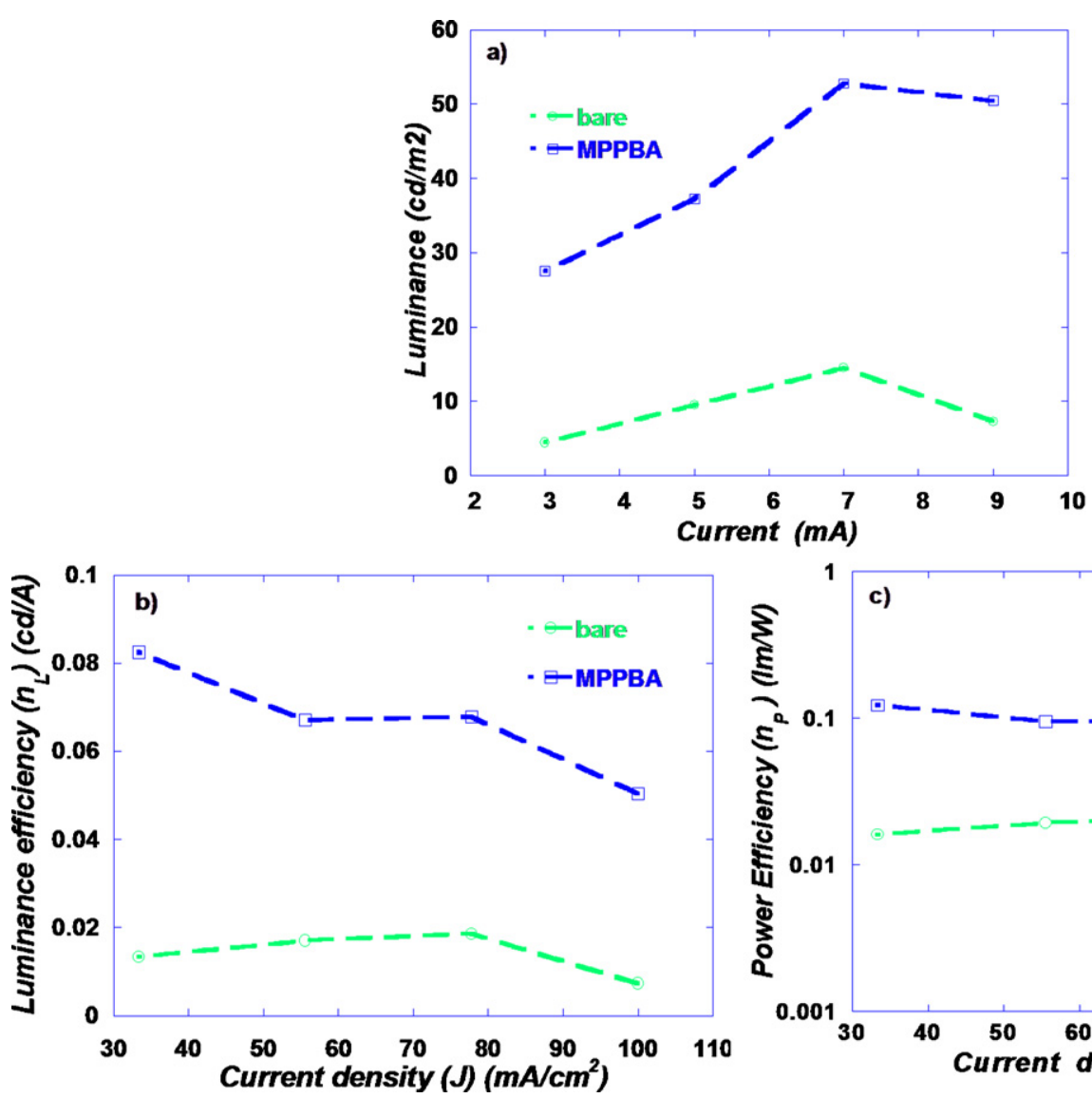

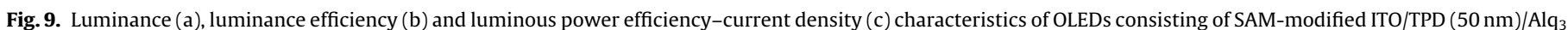
$(60 \mathrm{~nm}) / \mathrm{Al}(120 \mathrm{~nm})$.

Similar chemical shifts were also seen for $\mathrm{C} 1 \mathrm{~s}$ in a wide range of model organic compounds [42-45]. 0 1s spectra were fit and are shown in Fig. 7(c). Three peaks at 529.9, 531.1 and $533.6 \mathrm{eV}$ are assigned to $\mathrm{O}^{2-}$, carbonyl group $(\mathrm{C}=\mathrm{O})$, and $(\mathrm{C}-\mathrm{O})$ or $\mathrm{Sn}-\mathrm{O}$, respectively [46-48]. In ITO films, the low binding energy O 1 s component at $529.9 \mathrm{eV}$ is attributed to oxygen in the form of oxide, $\mathrm{O}^{2-}$ present on ITO surface $[49,50]$. Carbonyl group $(C=0)$ peak is the strongest signal among them.

\subsection{The OLED characteristics}

$I-V$ characteristics of the OLED device fabricated using SAMmodified ITO anode is shown in Fig. 8(a). According to this figure, when the OLED device was positively forward biased with respect to the cathode ( $\mathrm{Al}$ ) contact, a beneficial effect of SAM layer on the turn-on voltage was clearly observed. The turn-on voltages of OLED devices made with SAM-modified and bare ITO were measured as $4.5 \mathrm{~V}$ and $5.5 \mathrm{~V}$, respectively. On the SAM-modified ITO anode, a significantly increased hole injection current was obtained compared to bare-ITO and, as a result of better hole injection, the observed enhancement in the turn-on voltage was about $1 \mathrm{~V}$. This observation was also confirmed by an intensified electroluminescent emission (EL) obtained from the OLED device fabricated with SAM-modified ITO anode (Fig. 8b). The increase in the EL intensity should be a result of better hole transport due to the modification of ITO surface. Increase in the current density at the interface can be explained by inelastic tunneling mechanism over extra energy levels formed between HOMO and LUMO levels of aromatic MPPBA molecules with $\pi$-conjugated structure used as tunnel barrier at the interface [51-53].

\subsection{External quantum efficiency-current characteristics of OLED devices}

The luminance, luminance efficiency and luminous power efficiencies for all the devices, are shown in Fig. 9(a)-(c), respectively. The results show that OLED characteristics of the devices are clearly affected by the increased hole-current density as a result of SAM modification.

At low voltage values, the luminance efficiency and luminous power efficiencies of the devices with ITO substrates modified by using MPPBA molecules are higher than that of the bare-ITO device, pointing out that increasing the hole-current density enhances the balance of charge carriers at low voltages. However, the luminance efficiency and luminous power efficiencies of all the devices decrease in higher voltage.

\section{Conclusion}

A new type of SAM molecule, MPPBA as hole-injection layer, with $\pi$-conjugated structure and functional carboxylic head group was used to modify hydroxyl-rich ITO surfaces. The SAM-modified ITO surface was characterized by XPS and KPFM. KPFM was used to measure the change in the surface potential and work function before and after modification of ITO surface. The experimental results on MPPBA modified OLED devices (ITO/MPPBA/TPD/Alq $/ \mathrm{Al}$ ) show a decrease in the turn-on voltages and an enhancement in the diode current and EL intensity compared to OLED devices made with bare ITO substrates. The increase in the EL intensity of MPPBA modified OLED devices should be a result of increasing hole transport due to SAM modification of ITO 
surface. The increase in the hole transport is related with tunneling current density at the interface and can be explained with inelastic tunneling mechanism over extra energy levels established between HOMO and LUMO levels of aromatic MPPBA molecules with $\pi$-conjugated structure used as tunneling barrier at the interface.

\section{Acknowledgements}

This work was supported by TUBITAK under Grant No. TBAG108T718. We would like to thank Dr. S. Sivananthan from UIC (US) for providing XPS facilities at Microphysics Lab.

\section{References}

[1] J.J. Kim, M.K. Han, Y.Y. Noh, Semiconductor Science and Technology 26 (2011) 030301.

[2] Y. Yim, J. Park, B. Park, Journal of Display Technology 6 (2010) 252.

[3] J.T. Lim, J.H. Lee, J.K. Park, B.J. Park, G.Y.Yeom, Surface and Coatings Technology 202 (2008) 5646.

[4] E. Cantatore, D.M. de Leeuw, Materials Science in Semiconductor Processing 11 (2008) 199.

[5] T.W. Kelley, P.F. Baude, C. Gerlach, D.E. Ender, D. Muyres, M.A. Haase, D.E. Vogel, S.D. Theiss, Chemistry of Materials 16 (2004) 4413.

[6] Y. Choi, E.Y. Lee, W.U. Desheng, INEC: 3rd International Nanoelectronics Conference, 2010, p. 921.

[7] F. Wang, T. Xiong, X. Qiao, D. Ma, Organic Electronics 10 (2009) 266.

[8] M.A. Khan, W. Xu, K. Haq, X.W. Zhang, Y. Bai, X.Y. Jiang, Z.L. Zhang, W.Q. Zhu, Journal of Physics D: Applied Physics 41 (2008) 225105.

[9] M.B. Khalifa, D. Vaufrey, A. Bouazizi, J. Tardy, H. Maaref, Materials Science and Engineering C 21 (2002) 277

[10] J. Chu, Q. Huang, J.G.C. Veinot, H. Yan, T.J. Mark, Advanced Materials (2002) 14.

[11] S.F.J. Appleyard, S.R. Day, R.D. Pickford, M.R. Willis, Journal of Materials Chemistry 10 (2000) 169.

[12] A. Berlin, G. Zotti, G. Schianon, S. Zecchin, Journal of American Chemical Society 120 (1998) 13453.

[13] S. Besbes, H. Ben Ouada, J. Davenas, L. Ponsonnet, N. Jaffrezic, P. Alcouffe, Materials Science and Engineering C 26 (2006) 505.

[14] K.H. Lee, H.W. Jang, K.B. Kim, Y.H. Tak, J.L. Lee, Journal of Applied Physics (2004) 95.

[15] J. Chu, Q. Huang, J.G.C. Vienot, H. Yan, Q. Wang, G.R. Hutchison, A.G. Richter, G. Evmenenko, P. Dutta, T.J. Mark, Langmuir 18 (2002) 9958.

[16] L.W. Chong, Y.L. Lee, T.C. Wen, Thin Solid Films 515 (5) (2007) 2833.

[17] J. Lee, B.J. Jung, J.I. Lee, H.Y. Chu, L.M. Dob, H.K. Shim, Journal of Materials Chemistry 12 (2002) 3494.

[18] R.A. Hatton, M.R. Willis, M.A. Chesters, F.J.M. Rutten, D. Briggs, Journal of Materials Chemistry 13 (2003) 38.

[19] M.A. Baldo, M.E. Thompson, S.P. Forrest, Nature 403 (2000) 750.

[20] A. Ulman, Chemical Reviews 96 (1996) 1533.

[21] Q.L. Huang, J.F. Li, G.A. Evmenenko, P. Dutta, T.J. Marks, Chemistry of Materials 18 (2006) 2431.

[22] Q.L. Huang, G.A. Evmenenko, P. Dutta, P. Lee, N.R. Armstrong, T.J. Marks, Journal of American Chemical Society 127 (2005) 10227.
[23] Q.L. Huang, G. Evmenenko, P. Dutta, T.J. Marks, Journal of American Chemical Society 125 (2003) 14704.

[24] B.M. Silverman, K.A. Wieghaus, J. Schwartz, Langmuir 21 (2005) 225.

[25] I.L. Liakos, R.C. Newman, E. McAlpine, M.R. Alexander, Surface and Interface Analysis 36 (2004) 347.

[26] E.L. Hanson, J. Schwartz, B. Nickel, N. Koch, M.F. Danisman, Journal of American Chemical Society 125 (2003) 16074

[27] K. Midwood, M.D. Carolus, M.P. Danahy, J. Schwarzbauer, J. Schwartz, Langmuir 20 (2004) 5501.

[28] M.P. Danahy, M.J. Avaltroni, K. Midwood, J. Schwarzbauer, J. Schwartz, Langmuir 20 (2004) 5333.

[29] K.L. Purvis, G. Lu, J. Schwartz, S.L. Bernasek, Journal of American Chemical Society $122(2000) 1808$.

[30] M.C. Harris, S.L. Buchwald, Journal of Organic Chemistry 65 (2000) 5327.

[31] J.Dash, P.S. Shirude, S.D. Hsu, S. Balasubramanian, Journal of American Chemical Society 130 (2008) 15950.

[32] A. Vioux, J. Le Bideau, P.H. Mutin, D. Leclercq, Topics in Current Chemistry 232 (2004) 145.

[33] D.J. Milliron, I.G. Hill, C. Shen, A. Kahn, J. Schwartz, Journal of Applied Physics 87 (2000) 572.

[34] V.M. Bermudez, A.D. Berry, H. Kim, A. Pique, Langmuir 22 (2006) 11113.

[35] J.A. Bardecker, H. Ma, T. Kim, F. Huang, M.S. Liu, Y.J. Cheng, G. Ting, A.K. Jen, Advanced Functional Materials 18 (2008) 964.

[36] J.E. Malinsky, G.E. Jabbour, S.E. Shaheen, J.D. Anderson, A.G. Richter, T.J. Marks, N.R. Armstrong, B. Kippelen, P. Dutta, N. Peyhambarian, Advanced Materials 11 (1999) 227.

[37] S.E. Koh, K.D. McDonald, D.H. Holt, C.S. Dulcey, J.A. Chaney, P.E. Pehrsson, Langmuir 22 (2006) 6249.

[38] S. Khodabakhsh, D. Poplavskyy, S. Heutz, J. Nelson, D.D.C. Bradley, F. Murata T.S. Jones, Advanced Functional Materials 14 (2004) 1205.

[39] M.P. de Jong, L.J. van Izendoorn, M.J.A. de Voigt, Applied Physics Letters 77 (2000) 2255

[40] E.L. Hanson, J. Guo, N. Koch, J. Schwartz, S.L. Bernasek, Journal of American Chemical Society 127 (2005) 10058.

[41] M.A.W. Fox, K. James, Organic Chemistry, 2nd ed., Massachusetts Jones and Bartlett Publishers, Sudbury, 1997.

[42] N. Moussaif, C. Pagnoullea, J. Rigab, R. Jeromea, Polymer 41 (2000) 3391

[43] I.V. Plyuto, A.P. Shpak, J. Stoch, L.F. Sharanda, Y.V. Plyuto, I.V. Babich, M. Makkee J.A. Moulijn, Surface and Interface Analysis 38 (2006) 917

[44] D.T. Clark, H.R. Thomas, Journal of Polymer Science Part A Polymer Chemistry Edition 14 (1976) 1671.

[45] E.E. Ortelli, F. Geiger, T. Lippert, J. Wei, A. Wokaun, Macromolecules 33 (2000) 5090.

[46] D.W. Zeng, K.C. Yung, C.S. Xie, Surface and Coatings Technology 153 (2002) 210.

[47] F. Montagne, J. Polesel-Maris, R. Pugin, H. Heinzelmann, Langmuir 25 (2009) 983.

[48] E. Binkauskienea, A. Lugauskasa, M. Krunksb, I.O. Acikb, V. Jasulaitienea, G. Saduikis, Synthetic Metals 160 (2010) 906

[49] O.M. Diplas, L.H. Nordmark, D.M. Kepaptsoglou, J.M. Graff, C. Ladam, F. Tyholdt, J.C. Walmsley, A.E. Gunnaes, R. Fagerbergb, A. Ulyashina, Surface and Interface Analysis 42 (2010) 874.

[50] C. Yan, M. Zharnikov, A. Go, M. Grunze, Langmuir 16 (2000) 6208

[51] M.G. Simonsen, R.V. Coleman, Physical Review B 8 (1973) 12.

[52] W. Wang, T. Lee, I. Kretzschmar, M.A. Reed, Nano Letters 4 (2004) 643.

[53] G.C. Bazan, Journal of Organic Chemistry 72 (2007) 8615. 